\title{
INDIVIDUALIZATION OF DESIGN VARIATION IN CONSTRUCTION
}

\author{
Thomas Bock \\ Technische Universität München, Munich \\ thomas.bock@bri.ar.tum.de \\ Thomas Linner \\ Technische Universität München, Munich \\ thomas.linner@bri.ar.tum.de
}

\begin{abstract}
Mass Customization has been introduced and applied in a multitude of industries and should now be transferred and developed further for application in construction industry. Industrialized customization offers particular advantages compared to conventional construction as it allows addressing parameters relevant for individual and sustainable construction consequently and simultaneously. An efficient value system for industrialized customization in construction is realized through the consequent co-adaptation of business strategy, product structure, configuration process, supply chain management, customized production, assembly process, customer relation and remanufacturing processes to a highly flexible organisational entity. Advanced Japanese prefabrication companies as Sekisui Heim (Unit Method) and Toyota Home (Skeleton and Infill) are used in this research to identify and analyze determining parameters for the deployment of industrialized customization and the individualization of design variation.
\end{abstract}

KEYWORDS: Industrialization, Mass Customization, Complementarities, User-CoCreation, Japanese Prefabrication

\section{INTRODUCTION}

Individualized industrial fabrication of products through demand oriented, lean and resource saving production today gradually becomes a prerequisite for any enterprise. With recurring resource shortages, striking economic crisis and evolving social standards a new paradigm arises which forces industry not only to focus on competitiveness but also on designing sustainable products and manufacturing processes with equal respect on economic, social and environmental impacts, meanwhile delivering individualized products. A solution to simultaneously addressing all mentioned demands is offered by a concept called "Mass Customization" (Piller, 2006). MC is a strategic means for delivering user adapted or even personalized products at same or even lower cost than standardized mass production. Mass Customization has been introduced and applied in a multitude of industries up to now. Yet, in construction industry which still is characterized by high energy and material consumption, tremendous waste volume, harsh working conditions, expensive and unsuitable houses and a lack of reuse and recycling mechanisms (Bock et al., 2009b), neither industrialization nor mass customization have been deployed in a greater scale (Bock et al., 2009a) to tackle the mentioned problems. Therefore principles of industrialization and mass customization should be transferred and integrated to industrialized customization and the individualization of design variation in construction. Industrialized customization offers particular advantages 
compared to conventional construction as it allows addressing parameters relevant for customized and sustainable construction consequently and simultaneously.

\section{Identification and analysis of parameters relevant for industrialized customization on the basis of Japanese prefabrication industry}

In recent architecture customization is often interpreted as a tool for forming highly differentiated 3D shaped components or buildings. This surely is not wrong and it is an important aspect for architecture, yet it only covers one of a variety of co-adapted supprocesses of that what customization seen from its original economic or management point of view really means: Customization is a complex strategic means. Therefore Customization is not based on the plain control of a single process or CNC machine but on creating new crosscutting and interdependent organizational structures corresponding through streaming information and material flows. Customization's heart is besides information and communication technology the rigorous co-adaptation of business strategy, product structure, configuration process, supply chain management, customized production, assembly process, customer relation and remanufacturing processes. To unveil customizations full potential all processes mentioned have to be designed as complementary (Bock, 1988; Milgrom et. al, 1991) sub-processes of an overall system/organism.

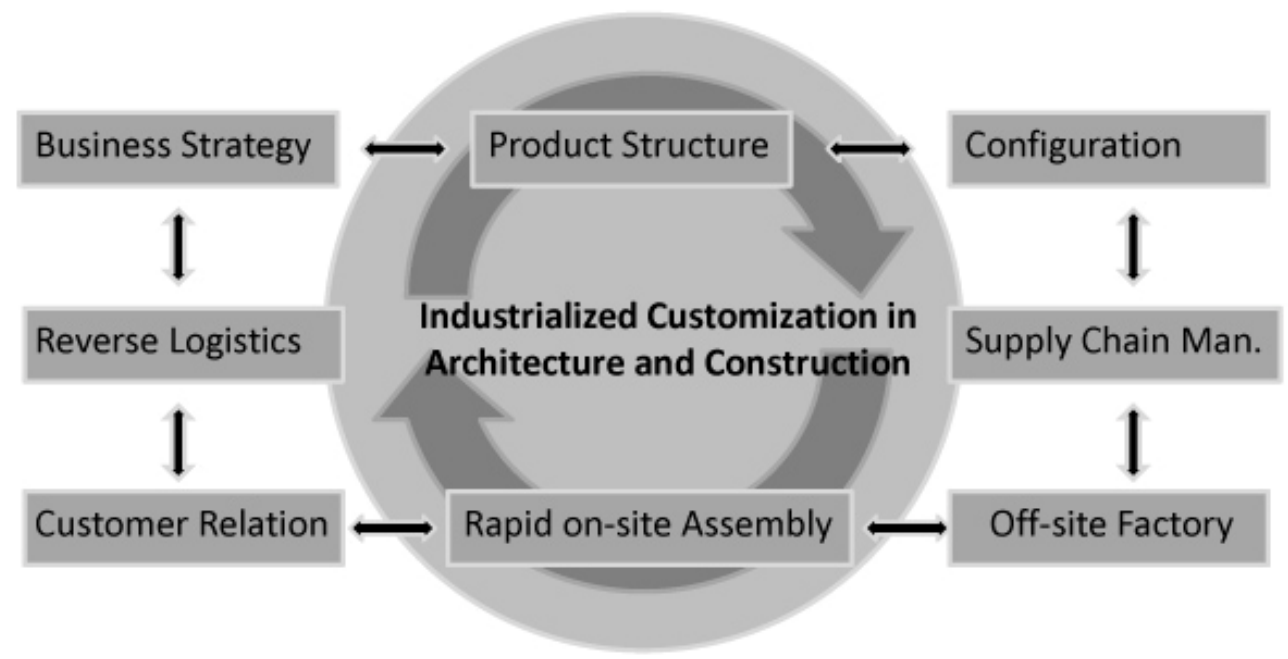

Figure 1: Co-adaptation and complementarities: prerequisites for individualization of design variation in construction

To identify, explain and analyze basic system requirements for industrialized customization and design variation in construction as well as to introduce the idea of complementary and co-adapted process, the advanced and industrialized fabrication systems of the Japanese prefabrication companies Sekisui Heim (Unit Method) and Toyota Home (Skeleton and Infill) have been examined. The following paper presents some of the research outcomes and gives an introduction to industrialized customization and its determining parameters.

\section{Customization as Business Strategy}

An important item in realizing Mass Customization is the development of an overall business strategy. The business strategy sets up basic parameters as for example intended degree of 
differentiation from other products, intensity of the customer experience and customer relation. The degree of customer integration chosen with the business strategy in order to achieve a certain market advantage further determines in particular product architecture, needed degree of flexibility of production systems, logistics structures and service strategies.

- Product Differentiation One of the main motivations for adopting customization strategies is the differentiation from products on the market and/or from competitors (Piller et al., 2003). With delivering customized or user adapted products or buildings a certain position on the market in relation to competitors is achieved.

- Creating Additional Value The more buildings are adapted to the preferences and life circumstances of inhabitants, the higher the subjective value to the inhabitant/customer is. Buildings can be adopted concerning a multitude of levels and sub-system groups, reaching from the plain design to functionalities determined by interior finishing and technical infill and integrated assistance technologies (Linner et al., 2009).

- Configuration as Experience Customization and thus the integration of the user and the user's knowledge through the configuration process to generate a unique product in general creates an experience for the customer (Pine et al., 1998). As buildings play an important role in most people's or families' life, the experience factor of co-creating the own home could be accounted as rather high.

- Customer Relation With delivering a differentiated product, creating additional value through adaptation and generating a configuration experience, an intense relation to the customer is established (Reichwald et al., 2006). Together with knowledge about the customer gained through the configuration process this relation could be used to establish a strong loyalty of the customer towards the enterprise. In housing industry this loyalty could be used for further value creation through life-cycle based services (Linner et al., 2009).

- Avoidance of Overproduction Customization is based on production according to the customers' individual and real needs and not on production according to market research and unsecure forecasts. Industrialized customization in building industry thus has a huge potential in reducing the amount of input resources (human, material, energy) in construction (Bock et. al., 2009b) meanwhile avoiding overproduction.

Japanese Prefab house builders as Sekisui Heim and Toyota Home are well aware of the business strategy parameters mentioned above. Each company uses them to create its own and unique brand experience and to underscore dedication towards the customer. In contrast to companies outside from Japan, the customization oriented business strategy of Japanese Prefab house builders is closely related to industrialized, highly automated and responsive production systems able to fabricate directly, fast and efficient.

\section{Product structure}

In customized prefabrication of individual buildings the product structure and its management through the whole life cycle (Lindemann, 2006) is the most crucial and most complex item in the process chain. The product structure has to be developed in respect of the needs of customized production. Japanese prefabrication companies have realized that with 
the beginning of large scale prefabrication in the 60ies and therefore have developed specific fabrication oriented designs and product structures.

- Construction Method The systems of Toyota and Sekisui are based on the combination of steel frame units to achieve the desired arrangement of a house. In general 10-15 units are combined to a complete house. The steel frame Units are used as "chassis" streaming through the factory being finished on specially designed production lines from all sides. Similar to a "chassis" in car industry, the steel frame unit later states the bearing structure. Technical infill as installations, cables and pipes can be seen as sub-components being attached to the "chassis" just-in-time just in sequence and just-on-demand.

- Structural decomposition "Super Skeleton and Intelligent Infill", Toyota calls its' structural organization system. This refers to the separation of the structural building components used as "chassis" (Skeleton) sub-systems and sub-components (Infill). This separation not only decouples the components but also decisions about design and functionality and allows for advanced parallelized production processes.

- Systemic multilevel grids Systemic grids for or each of the decoupled component families and subsystems are used both for coordinating the whole component system itself and for synchronizing the product structure with production system and supply chain. Within the given grids parts/components could be supplemented by others or even individually fabricated. Parts/components could be added or exchanged as long as they apply to the underlying modular coordination system.

- Open Engineering Systems OESs are open component systems that have the ability to be developed further or transformed into new product models or product lines by a company's system designer or engineer. Modularity could be distinguished basically into two types. One type is dedicated to the customization through customers and the other type is related to the producer giving him the ability to gradually develop further his products by exchanging and innovating particular sub-components. About ten new housing models and about 400 modifications and improvements to existing models are introduced annually for example by the Japanese company Sekisui Heim, making it necessary that the component systems have to be based on OES principles.

\section{Configuration process}

The design of the configuration process plays a crucial role in any customization strategy as it links the knowledge about the customer and his preferences to product structures, subsequent fabrication and delivery process. Generally we can distinguish between on-line and off-line configuration (Lindemann et al., 2006). In on-line configuration the configuration tool is directly used by the customer whereas in off-line configuration, the configuration process is guided and finally performed by a company member according to the customer's demands. As buildings are rather complex products, up to now, all Japanese Prefab house builders have been basing their configuration strategy on off-line configuration.

- Regional Operation Sekisui and Toyota offer different types of houses fitting to Japans regional, cultural and climatic differences. To get closer to the customers, also regional based model parks in strategically important areas have been established. Accordingly, 
factories are placed strategically in various areas where they finish houses according to the demands, materials and preferred housing types of the surrounding region. Nevertheless, those strategically placed factories are integrated into greater, nationwide production clusters and supply networks.

- Customer Integration Most prefabrication companies in Japan hold R\&D centres which are open to customers. Most R\&D canters are integrated with "showroom" and/or "living" areas where customers choose components, furniture and configurations. Customers are free to choose the degree of customer integration. The degree of customer integration still determines the price. Nevertheless, continuous process improvements are aiming at lowering cost impacts of high user adaptation gradually.

- Changeover Service If customers choose to buy a house of Sekisui or Toyota a pre contract is made fixing time schedules and changeover services. In general the configuration takes 1-4 month depending on the customer. After that factory production, on site delivery and assembly take about 1-2 month and the finishing and hand over one more month. The pre-contract further fixes accompanying services. For a relatively low additional changeover charge packages are available making the move to the new home a convenient thing. Those accompanying services have always been playing an important role in creating the positive image prefabrication has in Japan today.

\section{Supply Chain Management}

Innovative strategies for ERP and logistics determine the efficiency of the resource flow as they control the structures which bring resources to the company's value creation and input/output transformation system. Further they can control the circulation of the resources within the company's production processes. Just-in-time and just-in sequence industrialized production lowers input resources and inventory and has thus the potential to counter-balance additional costs of individual production. The "Kanban" system introduced by Toyota and Taichi Ohno with the Toyota Production System (Ohno, 1988) can be accounted as the precursor and enabler of innovative one-piece-flow systems of modern manufacturing (Piller, 2006) aiming at more and more individualization of products. Kanban and TPS have also been transferred from Toyota's automotive sector to Toyota's housing sector. Further Sekisui Heim's expert system (HAPPS, Heim Automated Parts Pickup System) has to be mentioned in the context of the evolution of advanced industrialized and demand oriented construction.

- Automated Component Selection Turning Sekisui Heim into highly productive company was initially enabled by its advanced IT based Enterprise Resource Planning System called HAPPS. As explained above, all houses are made of 10-15 steel frame units, each finished individually according to customers' demands. This means that every unit prefabricated in the factory is different. Therefore it is an important process to select and pick up about 30,000 components correctly for each house, out of about 300,000 components building up the solution space and feed them to the production line just in sequence (Furuse et al., 2006).

- Automated Task and Production Scheduling HAPPS is a parameter based system supporting the whole workflow: configuration, planning, receipt of order, logistics, fabrication and delivery. It helps to generate parts and component structures and parts 
lists from the CAD floor plans (Furuse et al., 2006). Based on the information generated from $\mathrm{CAD}$ models, logistics and production processes are controlled to a high degree automatically.

- One-Piece-Flow OPF refers to a production method where every entity or unit streaming on the main production line is allowed to be different. It is particularly important in industrialized housing industry where according to a high demand of individual designs and individual floor plans basically each steel frame unit being finished on the main production line should be different. Today, both Toyota Home and Sekisui Heim have adopted OPF principles sucessfully.
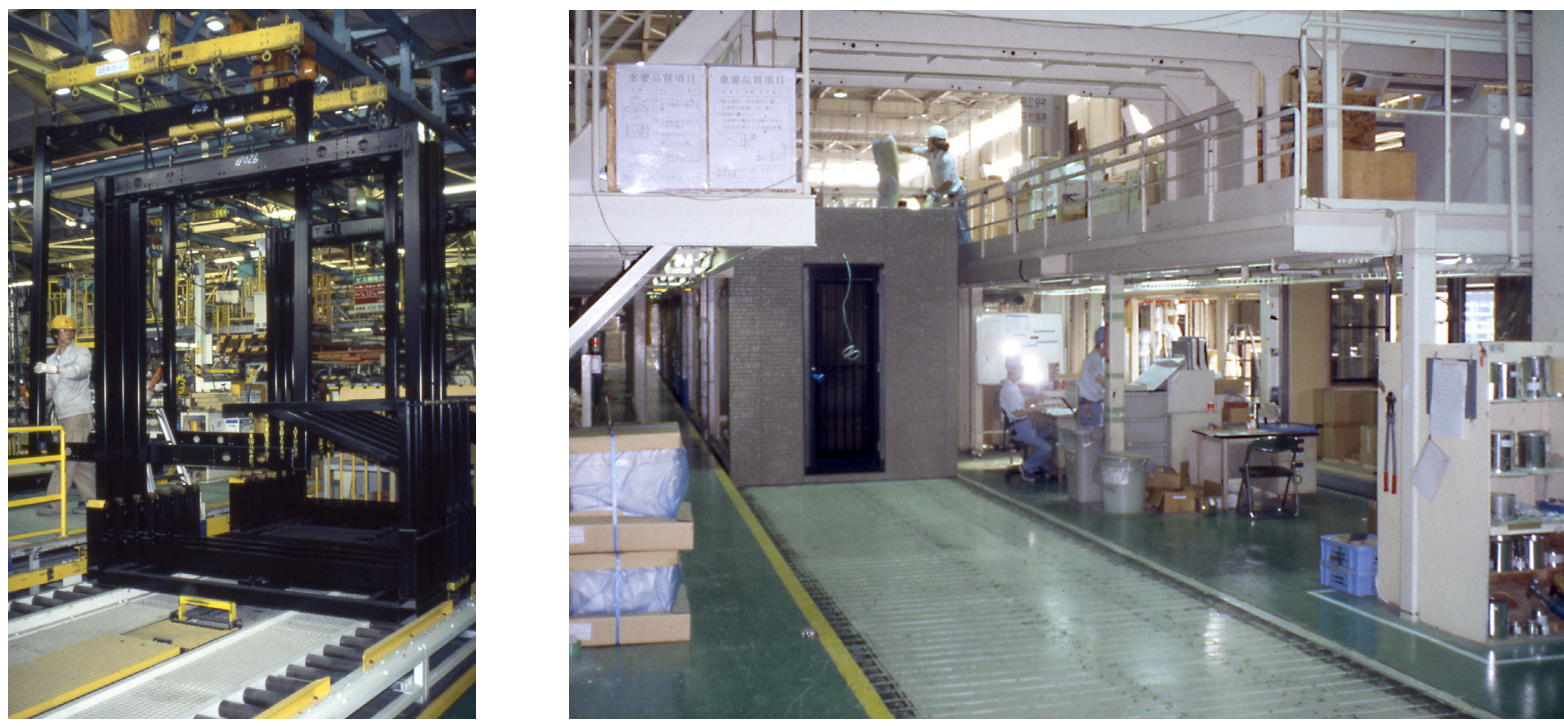

Figure 2: Fabrication of sub-elemts of the "chassis" skeleton, Toyoyta Home

Figure 3: 3-dimensional just-in-time just-in-sequence customized completion of individual Units on the production line, Sekisui Heim

\section{Customized off-site production}

Both the factory production of Sekisui and Toyota are based on assembly line production where the moving steel frame units are customized due to floor plans, functionalities, technical infill and finishes demanded by an individual customer. Sub-components are fabricated in parallelized processes on various floors. Sekisui Heim achieves up to $80 \%$ factory prefabrication (Sekisui Heim, 2009) and Toyota Home (Toyota Home, 2009) up to $85 \%$.

- Automated Steel Frame Production One of the basic workstations is the fully automated assembling and welding station. Into this station ceiling elements, flooring elements and columns are fed and then automatically welded to a frame which is in the further process used as a "chassis" and bearing structure able to be finished and processed 3-dimensionally from all sides (Figure 3) on a 400 meter long production line.

- Factory layout After automated welding, the steel frame "chassis" are streaming through the factory from workstation to workstation until they are finished with all installations. The factories of Sekisui and Toyota therefore offer gates on both sides of the assembly 
line where materials, parts and components demanded for the customized production of individual units are delivered just-in-time and just-in-sequence by cooperating suppliers.

- Minimal Waste Production Throughout the factory prefabrication, contrasting to conventional construction, a minimum of waste is generated. Both Sekisui and Toyota are aiming at zero-waste factories. This could be achieved on the one hand through the supply with modules fitting into the product structure without further processing or cutoff waste. On the other hand, remaining waste is fastidiously sorted within the factory at every workstation for reuse and recycling.

- Pre-Installation The pre-installation of furniture and cables is an important part of the production strategies of Sekisui and Toyota. The higher the degree of technical installation, the more efficient the prefabrication is. The factory environment thus turns out to be perfect for fast and high quality installation of complex technical infrastructure and complex performance added components/ sub-systems.

- Rigorous Quality Control Additionally to quality controls performed by robots, specially trained and qualified staff rigorously inspects quality after each production step/workstation. Each company has developed quality checklists for 200-300 different items for a house as early detection of mistakes saves time and cost. Additionally, an error-free product enhances the companies' reliability (Sekisui, 2009).

- Modularization of processes and equipment Throughout more than 30 years both Sekisui and Toyota have developed modular resource supply structures as well as modular production facilities. Due to constant changes in product structures and according to the recurring introduction of new housing types, applications, tools and machinery require a high degree of modularity and flexibility.
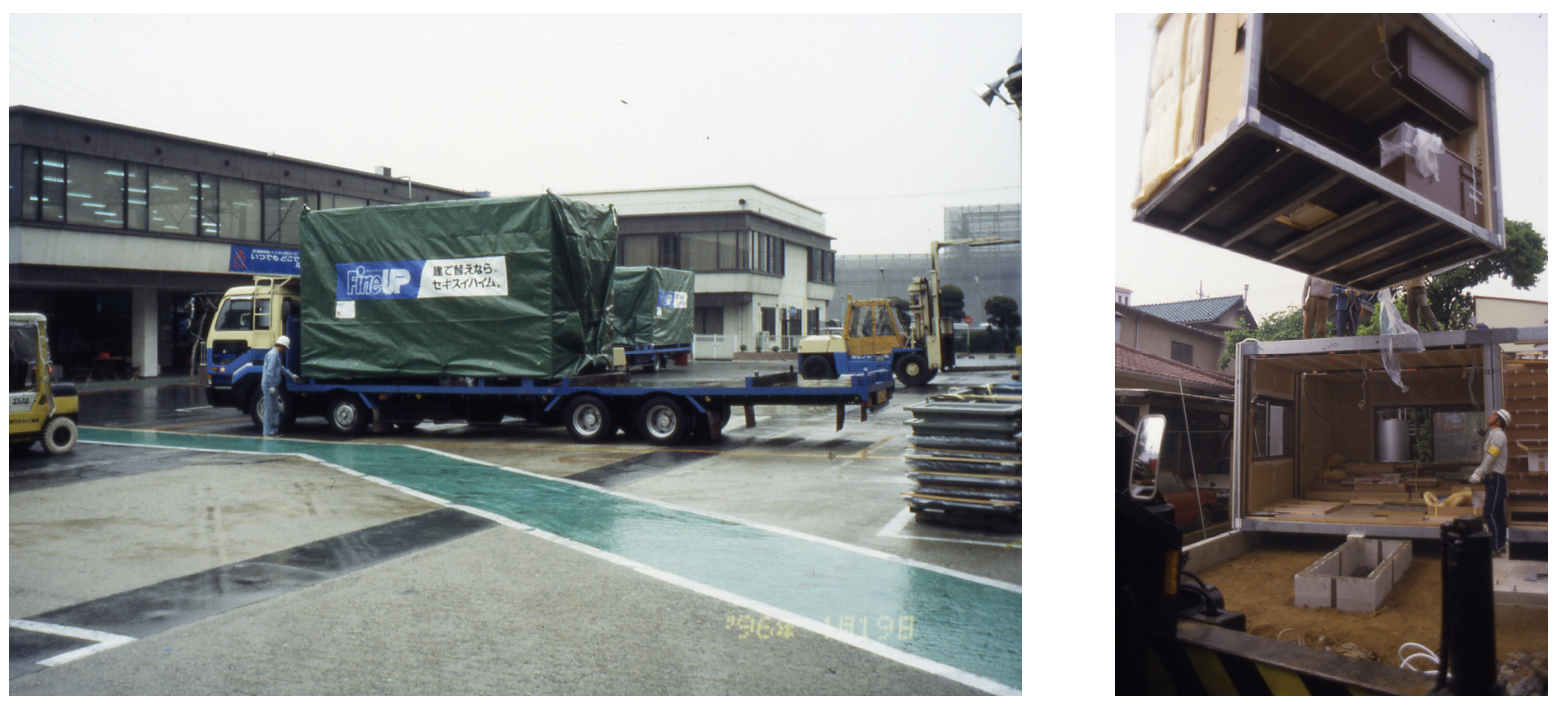

Figure 4: Transport of completed Units from the factory to the site Figure 5: Rapid assembly of pre-installed Units on the site 


\section{On-Site Assembly}

Industrialized, automated and customized prefabrication as performed by Sekisui and Toyota aims at shifting complexity and work intensive processes to the highly controlled factory environment. On-site work tasks are consequently reduced to simple unit joining processes and some less interior finishes. Therefore special joining mechanisms have been developed in accordance with the unit modularity for allowing a basic setup of a single family house within one day and without fixed crane or scaffolding.

- Just in-time delivery in the last factory workstation the completed and pre-installed units are packaged and brought to a temporary storage area. Later they are delivered on-site just-in-time and just-in-sequence of assembly operations by a group of transporters.

- Rapid Assembly The factory pre-installed and pre-finished steel frame units as well as the prefabricated roof modules are assembled on-site within one day. Thus the house becomes water proof and wind tight immediately and quality losses are avoided. Within the protected house specially trained assembly workers complete the finishing and remaining installations are performed in a convenient on-site working environment.

\section{Handover and Customer Relationship}

Attracting and retaining clients is essential to the success of any customization oriented strategy. Through the customization process the companies receive detailed information about the customer and also establish a relatively deep relation to the customer. During the life-cycle phase when a house is being used, the knowledge about the customer and the delivered product could be used further for efficient long-term maintenance. The established relation to the customer could moreover be used for after sales-services and additional lifecycle oriented value chains.

- Handover The handover of a house from Sekisui or Toyota is designed as an experience and is accompanied by typical Japanese service attitude. In most cases the move to the new home is done or at least supported by those companies with nor or just a few extra cost. When the house is handed over, the customers moreover receive a guiding handbook/manual for the new home.

- Quality certificates and warranty To prove performance, quality and durability of the house and its sub-systems, customers receive quality and warranty certificates with the handover of the house. As all individual houses have been fabricated in a highly controlled factory environment and all pre-production models have undergone rigorous quality test, similar to car industry, a high performance concerning durability and earthquake resistance could be guaranteed.

- Regular inspection and long term maintenance Toyota for example gives a warranty for 60 years on basic structure, facade, walls and roof, 30 years on all other elements and 5 years on frequently used elements as floors. During that time regular inspections by specially trained maintenance staff ensure that damages are repaired and claims are thus avoided proactively. Above that, the customers can choose from different long-term maintenance packages (Toyota, 2009). 
- Flexibility and renovation services Both Sekisui and Toyota offer the possibility that, due to changes in life style and household size/demands, modules/units can be added or exchanged (Toyota, 2009; Sekisui, 2009). Nevertheless, reorganizations could still be simplified; their systems' modularity, standardization and joining methods offer great potentials for continuous rearrangement and related services. Those services could take up and carry on the intense customer relation already established through the initial customization process for the creation of continuous value chains.

\section{Reverse Logistics and Remanufacturing}

All buildings of the Japanese Prefab maker Sekisui Heim which have been based on the steel frame unit system can be accepted as trade-ins for a new Sekisui Heim (Sekisui Heim, 2010) building. Therefore the deconstruction and remanufacturing process has been designed as a modified reversed version of the production and assembly process. For deconstruction first joints between steel frame units are eased and then the house is transported to a special dismantling factory unit by unit. There the outdated sub-components are dismantled and brought into advanced reuse cycles. The bare steel frame units are inspected and subsequently fed again into the production processes for customized and user-integrating prefabrication.

\section{CONCLUSION}

Industrialized customization in construction aims at unifying housing producers' demands and housing customers' demands in a continuous and intensifying relationship generating value for producer, customer and environment. A value system for industrialized customization in construction and the individualization of design variation is realized by the consequent co-adaptation of business strategy, product structure, configuration process, supply chain management, customized production, assembly process, customer relation and remanufacturing processes to a highly flexible and responsive organisational entity. Additionally, today with recurring resource shortages and economic crisis a new paradigm arises, and especially construction industry is forced to focus on both competitive advantage and sustainable/resource saving construction. Industrialized customization has particular advantages compared to conventional construction in addressing the mentioned issues simultaneously and with high efficiency. Further research will focus on the xtension and enhancement of the parameters identified and analyzed in this paper.

\section{REFERENCES}

1. Piller, F.T. (2006) Mass Customization. Wiesbaden: Deutscher Universitätsverlag

2. Bock, T., Linner, T., Lee, S.Y. (2009b) Integrated Industrialization Approach for lean On-/Off-site Building Production and Continous Resource Circulation. Proceedings of $7^{\text {th }}$ Global Conference on Sustainamble Manufacturing

3. Bock, T., Linner, T. (2009a) Structural Changes and Technology Utilization in German Construction. Tokyo: JCMA, Japan Construction Mechanization Association

4. BOCK, T. (1988) Robot Oriented Design. Tokyo: Shokokusha 
5. Milgrom, R., Qian, Y. Roberts, J. (1991) Complementarities, momentum, and the evolution of modern manufacturing: technology, strategy and organization. USA: The American Economic Review. 5: 84-88

6. Piller, F.T., Stotko, C. (2003) Mass Customization and Customer Integration. Düsseldorf: Symposion.

7. Linner, T., Bock, T. (2009) Smart Customization in Architecture: towards intelligent buildings. Proceedings World Conference on Mass Customization, Personalization and Co-Creation (MCPC), Helsinki

8. Pine, B. J., Gillmore, J. (1998) Welcome to the experience economy. Harvard Business Review, 76, Nr. 4 pp 97-106

9. Reichwald, R., Piller, F.T. (2006) Interactive Value Creation. Wiesbaden: 2006

10. Lindemann, U. Reichwald, R., Piller, F.T. (2006) Individualized Product. Berlin: Springer

11. Ohno, T. (1988) Toyota Production System - beyond large scale production, Massachusets: Productivity Press

12. Furuse, J., Katano, M. (2006) Structuring of Sekisui Heim automated parts pickup system (HAPPS) to process individual floor plans. Japan: ISARC 2006 International Symposium on Automation and Robotics in Construction

13. Sekisui Heim (2009) General Infermation

14. Tyota Home (2009) General Infermation

15. Sekisui Heim (2010) Japan, System Reuse House, available at: www.sekisuichemical.com/about/division/housing/reuse.html

16. Figure 2-5: Copyright T. Bock 